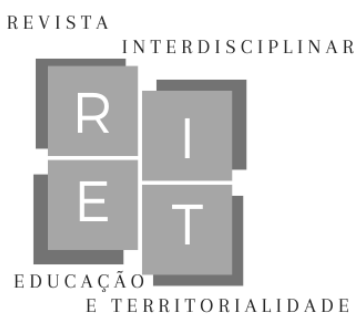

\title{
Os Kiriri de Jacobina e os riscos ambientais da exploração aurífera
}

\author{
The Kiriri of Jacobina and the environmental risks of gold mining \\ Pueblo Kiriri de Jacobina y los riesgo ambientales de la exploración de oro
}

Joelma Boaventura da Silva

Programa de Pós-Graduação em Difusão do Conhecimento, Universidade do Estado da

Bahia (UNEB)

Salvador, Bahia, Brasil

E-mail: jbomfim@uneb.br

ORCID: 0000-0002-7582-6662

\begin{abstract}
Almacks Luiz Silva
Comitê da Bacia Hidrográfica do Rio São Francisco (CBHSF)

Jacobina, Bahia, Brasil

E-mail: almacks@gmail.com

ORCID 0000-0001-7673-0825
\end{abstract}

Resumo: O objetivo principal deste artigo é situar as ilações histórica e sociais do povo Kiriri com o espaço jacobinense e as consequências dessas ilações no âmbito cultural, de proteção de direitos e ambiental. O presente trabalho discute a relação histórica do povo Kiriri com a região de Jacobina na Bahia a partir de aspectos linguísticos, históricos, sociais e ambientais. Discute-se também a legislação aplicável às barragens de rejeito, bem como a cultura Kiriri, além da questão ambiental vinculada à mineração de ouro no município de Jacobina, em especial, o risco atual de ruptura de barragem. Tal risco tem repercussão na alteração da paisagem, contaminação de corpos d'água, além de risco de morte para membros do agrupamento Kiriri. É um estudo interdisciplinar que utiliza várias fontes de consulta: jornais, textos técnicos, teses, dissertações, processos judiciais, legislações dados estatísticos, mapas e imagens, além da pesquisa empírica junto à comunidade indígena. $\mathrm{O}$ estudo conclui que a ameaça ao agrupamento Kiriri em Jacobina é uma realidade e acirra sua vulnerabilidade.

Palavras-chave: Povo Kiriri. Barragem. Mineração. Vulnerabilidade.

Abstract: The main objective of this article is to situate the historical and social illatons of the Kiriri people with the Jacobinense space and the consequences of those illations in the cultural, environmental and protection of rights. The present work discusses the historical relationship of the Kiriri people to the Jacobina Region in Bahia from linguistic aspects, social, historical and environmental. It also discusses the legislation applicable to waste dams, as well as the Kiriri culture, in addition to the environmental issue linked to gold. Gold mining in the municipality of Jacobina, in particular, the current risk of dam failure. This risk has repercussions on altering the landscape, contamination of water bodies, in addition to the risk of death for members of the Kiriri group. It's, therefore, an interdisciplinary study that uses various sources of consultation, from newspaper, technical texts, theses, dissertations to lawsuits, laws, statistical data, maps and images, in addition to empirical

RIET- ISSN 2676-0355, Dourados, v. 2, n. 2, p. 409 a 430, jan./jun., 2021. 


\section{Os Kiriri de Jacobina e os riscos ambientais da exploração aurífera}

research with the indigenous community. The study concludes that the threat to the Kiriri group in Jacobina is a reality, therefore, it is a form of hardening their vulnerability.

Keywords: Kiriri people. Dam. Mining. Vulnerability.

Resumen: El objetivo principal del artículo es estudiar las relaciones de este pueblo con Jacobina y sus consecuencias culturaes, ambientales y de la proteción de los derechos. El presente trabajo discute la relación histórica del pueblo Kiriri con la región de Jacobina Bahía en los aspectos linguísticos, históricos, sociales y ambientales. Análisis también la legislación bajo las represas de rechazo y también bajo la cultura Kiriri y la cuestión ambiental de la minería de oro en Jacobina, especialmente,lo riesgo actual de la ruptura de la presa. Esto riesgo tiene impacto em la paisaje, contaminación del agua, ademais hay el risco de morte para lo Pueblo Kiriri. Es un estudio interdisciplinar que utiliza varias fuentes como los periódicos, textos técnicos, tesis, disertaciones, hasta demandas judiciales, datos estadísticos, mapas e imágenes, además impíria junto a la comunidad indígena.El estudio concluye, que hay amenaza real al pueblo Kiriri en Jacobina, la cual es una forma de vulnerabilidad.

Palabras clave: Pueblo Kiriri. Represa. Minería. Vulnerabilidad.

Data de entrada: 07/04/2021

Data de aprovação: 10/06/2021

DOI: $10.30612 /$ riet.v2i2.14511

\section{Introdução}

Nos últimos anos, o Brasil tem sido cenário de desastres e crimes ambientais causados por rupturas de barragens que impactam a sociedade e tem uma conotação mais perversa quando vitimam povos originários. A pouca visibilidade dos problemas indígenas atravessa o tempo e gera com isso a perda de parte de nossa história, impactando no empobrecimento da academia que se distancia deste saber latente e necessário para as gerações futuras. $\mathrm{O}$ trabalho tem perspectiva interdisciplinar, pois analisa aspectos históricos, jurídicos, linguísticos, sociais e econômicos, utilizando de uma ampla revisão de literatura e análise dialética das informações.

O objetivo principal deste trabalho é mostrar que a vinculação entre os Kiriri e Jacobina remonta a longas datas e por várias nuances. Em segundo plano, objetiva esclarecer os riscos aos quais o agrupamento Kiriri em Jacobina está exposto ante o desgaste de barragens de rejeitos advindas de extração aurífera. A justificativa da temática abordada está na parca literatura sobre o tema, em especial sobre Povo Kiriri, atendendo-se assim ao ineditismo quando se esboça a relação deste povo com a região de Jacobina e a mineração. A relevância do trabalho decorre da exploração de tema multifacetado e da possibilidade de visibilidade acadêmica e social para o agrupamento étnico citado, que compõe hoje o universo dos invisíveis sociais.

RIET- ISSN 2676-0355, Dourados, v. 2, n. 2, p. 409 a 430, jan./jun., 2021. 


\section{Os Kiriri de Jacobina e os riscos ambientais da exploração aurífera}

Utiliza-se nesta obra várias fontes de consulta, as quais podem ser apresentadas didaticamente por áreas, a saber: documentos jurídicos através de inquérito civil do MP BA; legislação federal como Resoluções da ANM; antropologia, a partir de Brasileiro, Donato, Pagliaro, Carvalho e Vieira; História com base em Conceição, Farias e Rodrigues; na Estatística pelos portais do IBRAM e IBGE; na esfera jornalística por Moura, Jornal do Brasil e Jornal de São Paulo; além da área ambiental nas contribuições de Oliveira, Pinheiro e Sanches. Outras contribuições da ordem geológica também estão presentes no texto.

A metodologia empregada é de caráter misto, parte do trabalho de observação da comunidade estudada por parte de um dos autores, seguida do diálogo com aqueles atores sociais e o registro fotográfico do modo de vida deles. No segundo momento faz uma revisão de literatura, passando por análise de dados estatísticos; elaboração de mapas comparativos e utilização de imagens. A pesquisa empírica através do contato com a comunidade e da oitiva dos relatos forneceu as pistas para buscar na literatura histórica e nos dados oficiais as comprovações que resultaram na construção deste texto.

As conclusões são propulsoras de novas pesquisas e de aprofundamento do tema, pois traz a tona o descaso da empresa mineradora com os rejeitos produzidos na extração aurífera; expõe claramente o risco, ao qual, o agrupamento Kiriri, em sua localidade, e em caso de rompimento da barragem B1, pode ser alvo; escancara a eterna, reiterada e repetida vulnerabilidade dos povos indígenas no Brasil, além de colocar uma das temáticas indígenas sob olhar acadêmico. O texto contribuí para área jurídica e demais áreas supracitadas.

\section{Caracterização Espacial}

A área de estudo está circunscrita ao Piemonte da Chapada Diamantina ${ }^{1}$ no Estado da Bahia, onde se localiza a cidade de Jacobina. Geologicamente, o piemonte é a superfície de declive entre a montanha e a planície, neste caso, entre a Chapada, "grande superfície, por vezes horizontal, a mais de 600 metros de altitude" (OLIVEIRA, 1983, p.109) e as montanhas jacobinenses, pois a cidade tem altitude de 463 metros, rodeada por serras e morros. Uma outra característica do piemonte é sua composição geológica resultante de "acumulação de material muito heterogêneo, constituído de blocos, seixos, areias, argilas,

\footnotetext{
${ }^{1}$ Chapada Diamantina é uma região de serras, protegida na categoria de parque nacional, situada no centro do estado brasileiro da Bahia, onde nascem quase todos os rios das bacias do Paraguaçu, do Jacuípe e do Rio de Contas.
}

RIET- ISSN 2676-0355, Dourados, v. 2, n. 2, p. 409 a 430, jan./jun., 2021. 


\section{Os Kiriri de Jacobina e os riscos ambientais da exploração aurífera}

limo, que litrificado, constitui um fanglomerado". (OLIVEIRA, 1983. p.503), composição essa facilitadora e propícia para extração mineral.

\section{Jacobina}

Devido as condições geomorfológicas, brevemente descritas acima, a região de Jacobina apresenta-se vinculada à exploração de minérios, em especial o ouro, como bem depreende-se dos estudos de SANCHES (2017, p.1) “ já que existiam diversas atividades subsidiárias ao ouro, condição esta que promoveu também o aumento da criminalidade nas vilas Jacobina e Rio de Contas foram vilas fundadas através deste eixo econômico". Como destaque da desordem social pode-se citar o quase desaparecimento do serviço de ourivesaria, o qual foi responsável pelo cunho da Rua dos Ourives, na qual trabalhavam aproximadamente 20 ourives com a produção local. Da condição de vila, Jacobina foi elevada a município em 1722 e manteve a forma produtiva aurífera bem como um passivo de desordem social, seguida de desorganização ambiental, efeito tão comum em áreas de extrativismo mineral. Hodiernamente este município tem uma população de aproximadamente 80.518 habitantes, contido um contingente indígena em percentual de $2,4 \%$, nos quais, está o agrupamento do povo Kiriri.

\section{Mineração em Jacobina}

É impossível abordar Jacobina sem fazer referência a mineração de ouro conforme esclarece FARIAS (2008, p.43) que "o povoamento em Jacobina, segundo a literatura produzida na Bahia, teve início no século XVII, mas foi a produção aurífera, iniciada na segunda metade do século XVII e intensificada no século XVIII, que promoveu o crescimento da localidade [...]". De forma industrial, tem-se o marco temporal de 1884, pois segundo JESUS (2005), através do Decreto Imperial 9.242 de maio daquele ano concedeu "o direito a Eduardo Dias e Moraes de explorar as serras de Jacobina ampliado pelo decreto 9705 de 29 de fevereiro de 1887. Foi montada uma instalação com pesados pilões californianos em Itapicuru, ao sul de Jacobina". (JESUS (2005, p.42). Essa instalação montada denominou-se Companhia das Minas de Jacobina vindo a falência em 1897 e deixando de passivo as instalações na área citada. Entre 1897 e 1930, a exploração aurífera em Jacobina não teve repercussão industrial, vindo a ser reativada no século passado, especificamente em 1930. Nas palavras de FARIAS (2008, p.29) "quando um comerciante chamado Leonídio Miranda se tornou um dos grandes exploradores do serviço do ouro trazendo consigo cerca de 300 garimpeiros a título de faiscação de ouro. Ali se instalou

RIET-ISSN 2676-0355, Dourados, v. 2, n. 2, p. 409 a 430, jan./jun., 2021 


\section{Os Kiriri de Jacobina e os riscos ambientais da exploração aurífera}

formando o atual povoado de Itapicuru”. Essa atividade é barrada judicialmente e a Companhia da Minas de Jacobina retoma sua propriedade. Em 1947 essa Companhia é sucedida pela "Mineração de Ouro de Jacobina Ltda, que em 1950 é vendida à empresa canadense Mineração Northfield Ltda que permaneceu em Jacobina até 1960. “(FARIAS, 2008, p.30). A década de 1960 foi marcada pela paralisação das atividades extrativista minerais na cidade, sendo retomada em 1973 através de pesquisas geológicas sobre a responsabilidade da UNIGEO, "uma associação entre empresa ICOMI e a Anglo América Sul Africana no Brasil para explorar as serras em Jacobina" (FARIAS, 2008, p.32). Nas décadas de 1980 e 1990, a empresa Mineração Morro Velho assume a exploração aurífera tendo por base os trabalhos anteriores de pesquisa. Atualmente as atividades mineradoras estão vinculadas a empresa canadense Yamana Gold.

Há um elemento essencial na produção aurífera: uso da água. Este uso traz vários desdobramentos, como por exemplo construção de barragens para captação da água; barragens para contenção de rejeito/dejetos da mineração; e poluição dos corpos d'água. Neste trabalho concentrar-se-á nas barragens de rejeito/dejetos decorrentes da mineração em Jacobina, em especial ao sul da cidade, nas comunidades de Itapicuru e Canavieiras. Tais barragens são denominadas B1 e B2.

\section{Situação da Barragem}

Após o período de pesquisa, iniciou-se a exploração e a construção da barragem de rejeito (B1), inicialmente pelo método de linha de centro e na década de 1990 a empresa mineradora assumiu a responsabilidade arriscadíssima da construção de barragem sob o método a montante (igual as barragens da Vale que se romperam em Mariana e Brumadinho - MG). Segundo a Agencia Nacional das Águas - ANA, em seu Relatório de Segurança de Barragens $^{2}$, deve-se observar que as barragens de contenção de rejeitos são construídas com o próprio material proveniente da atividade minerária ou industrial. Com base na estrutura inicial de contenção, denominada dique de partida, os rejeitos são lançados para armazenamento, formando um depósito com uma zona denominada praia e outra denominada lagoa de decantação. A partir do momento em que a capacidade operacional da barragem de rejeito é atingida, necessário se faz, que o dique de partida seja elevado gradualmente, para acumular mais resíduos. Esse processo é denominado de alteamento, e

${ }^{2}$ Relatório de segurança de barragens/ 2018 disponível no site https://www.ana.gov.br/noticias/ana-lancarelatorio-de-seguranca-de-barragens-2018

RIET- ISSN 2676-0355, Dourados, v. 2, n. 2, p. 409 a 430, jan./jun., 2021. 


\section{Os Kiriri de Jacobina e os riscos ambientais da exploração aurífera}

pode ser executado, geralmente, de três formas diferentes, tendo como referência a direção em que a crista de alteamento se desenvolve em relação à posição inicial do dique de partida.

Devido ao risco de deslizamento deste tipo de barragem, sua utilização está proibida pela Agencia Nacional de Mineração - ANM em todo o território nacional, desde fevereiro de 2019. Além disso, a ANM estabeleceu prazos para descaracterização das barragens à montante, existentes, a depender do volume da barragem. As barragens de rejeito localizadas na área sul de Jacobina, principalmente a B1 deve ser descaracterizada para adequação às normas vigentes. $\mathrm{O}$ prazo dado para que as companhias mineradoras façam a descaracterização das barragens à montante é 25 de fevereiro de 2022, embora a Resolução $\mathrm{N}^{\circ} 13 / 2019$ da ANM, determine prazos escalonados até 2027, de acordo com o porte da barragem. A compatibilização dos prazos será ajustada entre os órgãos públicos competentes para a temática. No entanto, as condições de desgaste da barragem são cercadas de ocultamento de informações por parte da Yamaha Golden gerando inclusive ação do Ministério Público do Estado da Bahia, através do Inquérito Civil nº 702.9.76928/2017 / Seção Jacobina.

Ressalta-se que a cidade cresceu em direção a área de exploração de ouro e seguindo o curso dos rios, portanto as condições de desgaste de tais barragens de rejeito efetivam risco para toda a cidade, mas com ênfase nas aglomerações residências mais próximas, a exemplo do povo Kiriri que se encontra na parte sul da cidade. Essa caracterização da região neste artigo permite situar a interface com os povos Kiriri e mineradora.

\section{Caracterização Étnica}

Temos uma variedade significativa de grupo indígenas e suas línguas, pois "200 povos, falantes de aproximadamente 180 línguas, distribuídos em praticamente todo o território nacional, em áreas rurais e urbanas, com características sociais e culturais, bem como trajetórias históricas, econômicas e políticas, as mais diversas” PAGLIARO (2005,p. 105). Cabe ressaltar que as fontes embasadoras sobre os Kiriri são parcas, porém muito relevantes. Uma observação inicial incide sobre a grafia do nome deste povo. Em fontes mais antigas esta grafia aparece "Kiriri" e em fonte mais atuais aparece "Kiriri", portanto, usamos as duas grafias neste trabalho.

Assevera-se com base em PAGLIARO (2005, p. 245) que as maiores perdas populacionais ocorreram "entre os povos que tiveram contato com frentes agrícolas,

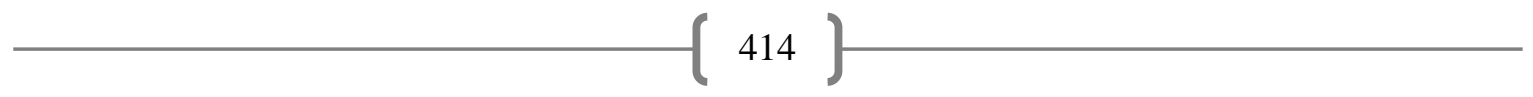

RIET-ISSN 2676-0355, Dourados, v. 2, n. 2, p. 409 a 430, jan./jun., 2021. 


\section{Os Kiriri de Jacobina e os riscos ambientais da exploração aurífera}

seguidos dos que se defrontaram com as expansões extrativistas e pastoris". Infere-se que o extrativismo mineral foi, é, e pode ser uma das condicionantes de mortalidade, extermínio e dizimação dos povos originários. Ainda dentro da caracterização do povo Kiriri merece destaque a diversidade étnica da Bahia no início do século XVI incluindo o povo em estudo. Os Caetés, Tabajaras e Icós ocupavam, no início da colonização brasileira, a área do Estado da Bahia. Segundo Rodrigues (2019), a família linguística Kariri, foi incluída no tronco Macro-Jê e o povo Kiriri utiliza, esporadicamente, alguns fragmentos do dialeto kipeá da família linguística Kariri. Sendo assim, os Kiriri são "falantes de Kariri, pertencentes ao grupo étnico tupiniquim “(Jornal do Brasil, 1971, p. 38).

\section{Breve História Dos Kiriri}

A primeira informação sobre a existência dos Kiriri no interior da Bahia aparece no Alvará da Coroa Portuguesa no século XVI. Um dos marcos importantes da história dos Kiriri ocorreu em 1758 e "extingue todos os aldeamentos e funda a Vila de Canabrava de Santa Tereza de Jesus dos Kiriri, que mais tarde seria denominada Vila de Pombal" (KIRIRI,2014, p.20). Merece destaque a participação dos Kiriri na Revolta de Canudos, no final do século XIX. Segundo Reesink (2012) foi o contexto da luta que contribuiu com sua "ciência de índio" e seus poderes xamânicos para o enfrentamento das tropas republicanas. A significativa participação Kiriri nesta revolução, levou a morte de aproximadamente 500 membros desta etnia. A mitigação de seus direitos durante o século XIX é denunciada por CARVALHO (2012, p.247/248),

nos anos noventa do mesmo século XIX, no entanto, mesmo esta tênue proteção deixou de existir e os índios passaram um período à mercê da sociedade regional, e, em particular, dos mais poderosos, portadores de títulos da Guarda Nacional

Percebe-se da transcrição, portanto, que os Kiriri estavam numa posição, especialmente, enfraquecida no quadro do sistema das relações interétnicas. Os conflitos em Canudos, área do nordeste da Bahia, acontece nos anos de 1896 e 1897, no mesmo lapso temporal em que a proteção aos Kiriri é retirada, promovendo assim uma identidade de discurso entre o "visionário" Conselheiro e os povos originários. No século XX, a luta pela terra Kiriri se intensificou ante a diáspora sofrida e o ano de 1949 aponta para a reclamação formal da terra originária através do Serviço de proteção ao Índio com instalação de um 


\section{Os Kiriri de Jacobina e os riscos ambientais da exploração aurífera}

posto em Mirandela ${ }^{3}$. No mapa a seguir visualiza-se distintamente a área originária dos Kiriri em Ribeira do Pombal e a subsequente área regulamentada em- Banzaê.

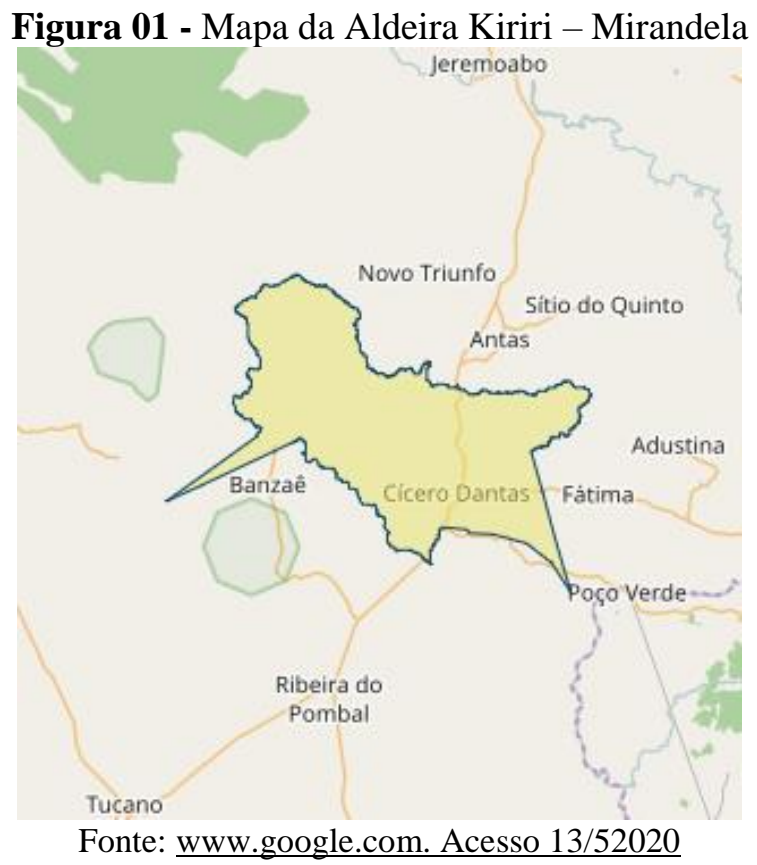

A vida precária em 1949 decorrente da mudança forçada de Ribeira do Pombal para Banzaê, passando pela redução da terra e pelo empobrecimento cultural e social se reificam na luta dos Kiriri na década de 1970. Os anos de 1972 com a instituição da FUNAI e 1976 com a mudança do chefe do Posto local foram importantíssimos para a reconquista da terra demarcada. Em abril de 1983, finalmente as terras foram retomadas após indenização paga pelo INCRA e FUNAI a fazendeiro que ocupava e explorava a terra Kiriri. Alguns anos mais tarde, em 1989, mais uma vitória deste povo, quando " $85 \%$ do território Kiriri passa a compor o município de Banzaê, desmembrado de Ribeira do Pombal" (BRASILEIRO, 2018). Por fim, na década de 1990, esse povo teve a demarcação de suas terras, com uma área de 12.320ha, homologada através do ${ }^{4}$ Decreto $n^{\circ} 98.828 / 90$. Atualmente o município de Banzaê, segundo IBGE tem uma população de 2.172 indivíduos com base no censo 2010.

A presença dos Kiriri em Jacobina é notada por volta do ano de 2005 devido dissidência de alguns membros da aldeia localizada em Banzaê, segundo relato dos próprios

\footnotetext{
${ }^{3}$ Mirandela é aldeia Kiriri na localidade de Banzaê, que foi desmembrado de Ribeira do Pombal.

${ }^{4}$ Em 15 de Janeiro de 1990, o decreto n 98.828, da Presidência da República, cria, nos territórios de banzaê e Ribeira do Pombal, terras indígenas para os Kiriri. Dentro dessas terras pertencentes ao município, existem sete comunidades indígenas: Sacão, Cacimba Seca, Canta-Galo, Lagoa Grande, Baixa da Cangalha, Marcação e Picos, sendo estes os núcleos tradicionais.( https://pt.wikipedia.org/wiki/Banza\%C3\%AA).
}

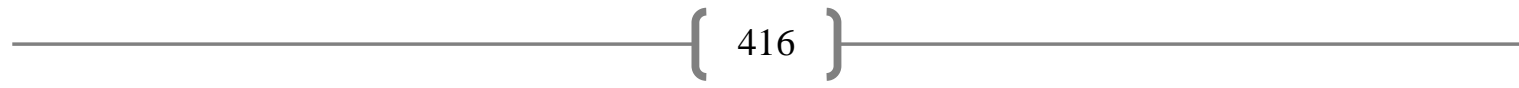

RIET- ISSN 2676-0355, Dourados, v. 2, n. 2, p. 409 a 430, jan./jun., 2021. 


\section{Os Kiriri de Jacobina e os riscos ambientais da exploração aurífera}

dissidentes. Em 2017 esse grupo residente em Jacobina tornou-se objeto de pesquisa ${ }^{5}$, pois apesar de contribuírem economicamente para o município, ainda eram e são invisíveis sociais. Este grupo dissidente, sem território demarcada em Jacobina, é um potencial contingente humano passível de sequelas irreversíveis, que possui ilações anteriores com Jacobina.

\section{Ilações históricas dos Kiriri com Jacobina}

Conforme noticiado na imprensa nacional "na segunda metade do século XVII (1666), formou-se uma expedição jesuítica - Missão das Jacobinas - com a finalidade de catequizar os índios do nordeste baiano" (JORNAL DO BRASIL, 1971. p. 38). Aqui, nos parece o primeiro elo de ligação entre os Kiriri e Jacobina, tendo em vista que a área de Jacobina era tão grande que se usava o termo declinado no plural (Jacobinas). O objetivo daquela expedição era a catequese dos índios do nordeste da Bahia, região que inclui a atual Ribeira do Pombal, área inicial de habitação dos Kiriri. Em apertada síntese, a Missão das Jacobinas serviu para catequisar os antepassados dos Kiriri. Juridicamente encontra-se outra ilação dos Kiriri com Jacobina, pois aquela comarca ao "princípio era assas vasta, porém foi coarctada por ocasião da criação das do Rio-de-Contas e de Centocé. Na prática tudo que não estava na jurisdição da comarca da Bahia e de Cachoeira era comarca de Jacobina no princípio" VIEIRA FILHO (2002, p. 12). Tal contexto do século XVIII é afirmado por CONCEIÇÃO (2017, p. 4):

a comarca de Jacobina foi, portanto, desmembrada da comarca da Bahia e houve motivos para tal separação, pois o território do interior da capitania passou a ser alvo de atenção da coroa, quando no século XVIII suas povoações foram sendo transformadas em vilas.

Excluindo-se o litoral e o Recôncavo baiano, todo o resto territorial, estendendo-se por Minas Gerais, Pernambuco e Sergipe, faziam parte da jurisdição de Jacobina. O nordeste da então província baiana é anexado à citada comarca ainda no século XIX como bem esclarece CONCEIÇÃO (2017, p. 16) “fazia-se necessário anexar à comarca da Jacobina as

\footnotetext{
${ }^{5}$ Outra experiência significativa de valorização dos coletivos diversos foi o desenvolvimento do Projeto "A cultura dos povos indígenas Kiriri na cidade de Jacobina-BA, elaborado em 2017 por alguns estudantes do curso técnico em comércio do CEEP Professora Felicidade de Jesus Magalhães, que se propuseram a pesquisar tal temática com a intenção de aprenderem sobre a história dos povos Kiriri e os ensinamentos que em família eles transmitem por gerações, sejam por meio dos artesanatos, das narrativas contadas, das festas vivenciadas e dos saberes medicinais. Para, além disso, visavam também contribuir para uma maior visibilidade destes povos tradicionais, já que era uma etnia pouco conhecida mesmo se fazendo presente comercializando objetos artesanais em nossa cidade" (LIMA; SANTOS; SILVA, 2018).
}

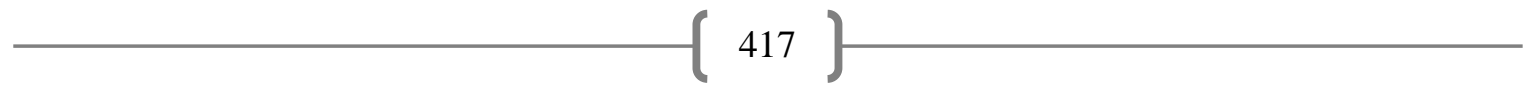

RIET- ISSN 2676-0355, Dourados, v. 2, n. 2, p. 409 a 430, jan./jun., 2021. 


\section{Os Kiriri de Jacobina e os riscos ambientais da exploração aurífera}

vilas do Itapicuru e Rio Real, que ficavam localizadas no 'sertão de baixo', distantes 80 léguas da vila de Jacobina" O motivo de tal anexação incidia sobre "a necessidade de aumentar o território de jurisdição de sua comarca, posto que a ampliação desta jurisdição, dava-lhe mais poderes para intervir junto a outras localidades" CONCEIÇÃO (2017, p. 16). Vale ressaltar que o pedido de anexação foi aceito e a partir daí os caminhos jurisdicionais de Kiriri e Jacobina se reencontram, incluindo-se a Bacia Hidrográfica do Rio Itapicuru. Os Kiriri passaram a pertencer à comarca de Jacobina a partir da ampliação desta. A abrangência da comarca de Jacobina baseada na sertania (os sertões) tem como pressupostos: a expansão do gado e a descoberta do ouro.

O primeiro pressuposto tem referência em SANTOS (2011, p. 67) a um dos caminhos da criação de gado que passava por "Pombal no Itapicuru, Jeremoabo no Vasabarris, atingindo o São Francisco acima da região encachoeirada". O Outro caminho dependia da expansão do gado e da passagem das Jacobinas para Juazeiro. Os pés dos bovinos, fora da área litorânea fazia das Jacobinas uma rota de tal importância que justificava a instituição de Comarca e também por isso as Jacobinas se tornou "um nome opulentado de grandezas e de misérias por seus metais e índios bravos" (SANTOS, 2011, p.20) - Kiriri e o ouro - como hoje ainda se configuram e se paralelizam, além de "um local de múltiplos encontros e contatos que foi um importante teatro de expansão da fronteira colonial e da resistência e adaptação de diversos grupos indígenas"(SANTOS, 2011, p. 20). Assim, a história com agentes diferentes, geracionalmente postos, se "repete". O segundo pressuposto, o ouro, corroborou para justificar tal amplitude da comarca quando a "situação tornou-se mais aguda com o descobrimento de minas de ouro, tanto na Bahia, quanto em Minas Gerais" (CONCEIÇÃO. 2017, p. 04).

Outra interface entre os Kiriri e Jacobina recaí sobre os aspectos linguísticos pois “do ponto de vista linguístico, os Payayá, juntamente com os Sapoiá, Maracás, Moritises e Tocós faziam parte da família Kariri, ramo vinculado ao tronco macro-jê” (SANTOS. 2011 p.36). Os Payayá, (predominantes em Jacobina) “juntamente com outros grupos da família Kariri (Kiriri), dominavam o sertão ao sul do São Francisco" (SANTOS. 2011 p.36), então o enlace linguístico é outro elo inconteste da relação entre o território jacobinense e o povo Kiriri.

Recentemente em decorrência de dissidência no grupo Kiriri em Banzaê, cerca de 50 indivíduos daquela comunidade migraram para a região sul de Jacobina, denominada de

RIET-ISSN 2676-0355, Dourados, v. 2, n. 2, p. 409 a 430, jan./jun., 2021. 


\section{Os Kiriri de Jacobina e os riscos ambientais da exploração aurífera}

Canavieira, nos arredores da área de exploração aurífera. Esta é, portanto, a nova e mais recente interface entre Kiriri e Jacobina e que é analisada neste trabalho sob a perspectiva ambiental.

\section{Modus de vida em Jacobina}

Uma vez apresentados os aspectos históricos que embasam este trabalho, é cabível descrever a produção aurífera em Jacobina, hodiernamente, bem como a forma de vida que foi engendrada pelos Kiriri desde 2005 nesta localidade, Pontilhão da Canavieiras. Esclarece-se que a descrição do modo de vida deste povo far-se-á com base no relato dos indivíduos e da observação dos autores in locu, tendo em vista, que um deles reside no município de Jacobina e mantém contato regular com a comunidade estudada.

\section{Da atividade de extração mineral}

Para a produção aurífera, necessário se faz uso de água bruta, que no caso deste estudo, incide sobre a Bacia Hidrográfica do Rio Itapicuru, em especial, sobre o Rio Itapicuruzinho. O uso da água está regulamentado na forma de outorga, que pode ser de dois tipos: captação e lançamento de efluentes. A mineradora Yamana Gold possui outorga de captação no Rio do Cuia, através de barragem própria, bem como outorga de lançamento de efluentes no Riacho Santo Antonio, tributário do Rio Itapicuruzinho. Para o modelo de exploração de ouro em Jacobina, forçosa foi a implantação de barragens para contenção dos rejeitos da mineração. As barragens de rejeitos B1 e B2 têm outorga de lançamento de efluentes fornecida pelo Instituto de Meio Ambiente e Recursos Hídricos - INEMA, via Riacho Santo Antônio que faz a conexão com o Rio Itapicuruzinho e por sua vez com o Rio Itapicuru-Mirim que desce para formar a Barragem de Pedras Altas no município de Capim Grosso. Em 2018 foi construído um sistema adutor interligando a Barragem de Pedras Altas a Barragem de Ponto Novo, no município de mesmo nome e consequentemente ao sistema adutor do Rio Jacuípe, que pela salinização das águas da Barragem de São José de Jacuípe, adiciona-se $40 \%$ (quarenta) por cento das águas do sistema integrado Pedras Altas/Ponto Novo, que é responsável pelo abastecimento de aproximadamente 2 (dois milhões) de pessoas. Os municípios de Jacobina, Caém, Saúde e Caldeirão Grande são abastecidos pela barragem de Pindobaçu que pertence a outro sistema, porém todos eles utilizam rios e afluentes da Bacia Hidrográfica do Itapicuru.

A barragem de rejeito B2 tem a concepção de construção pelo método a jusante (mais segura e moderna), e é revestida de mantas termoplásticas de polietileno de alta densidade (PEAD), o que oferece uma maior segurança e melhor adequação ambiental.

RIET-ISSN 2676-0355, Dourados, v. 2, n. 2, p. 409 a 430, jan./jun., 2021. 


\section{Os Kiriri de Jacobina e os riscos ambientais da exploração aurífera}

Segundo a mineradora, Yamana Golden, até o ano de 2036, essa barragem atingirá a altura de 92 (noventa e dois) metros de altura e terá capacidade para mais de 42 (quarenta e dois) milhões de toneladas de rejeitos. A empresa, porém, cometeu o erro gravíssimo de construir esta barragem a jusante (área abaixo) da problemática barragem / B1, comprometendo completamente a estrutura moderna e segura da B2. (informe retirados do Inquérito Civil $\mathrm{n}^{\circ}$ 702.9.76928/2017 do Ministério Público da Bahia/ Seção Jacobina). Na foto a seguir, temse uma visão clara das referidas barragens e percebe-se sua disposição.

Figura 02 - Visão de barragens B1 e B2

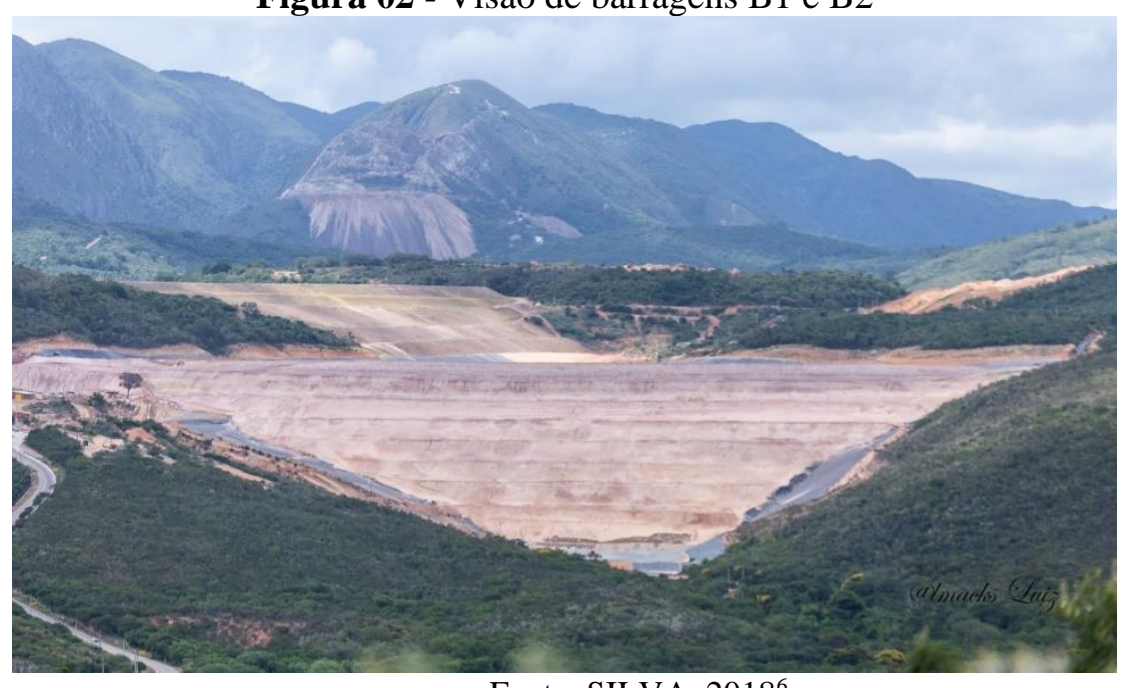

Fonte: SILVA, $2018^{6}$

A Resolução No 4/ 2019, do Ministério de Minas e Energia em conjunto com a Agência Nacional da Mineração - ANM, estabelece medidas regulatórias e cautelares objetivando assegurar a estabilidade de barragens de mineração, notadamente aquelas construídas ou alteadas pelo método denominado de "montante", que é o caso da B1 da Yamana Gold em Jacobina. Neste sentido, a referida Resolução prevê a

proteção dos recursos naturais e à manutenção da incolumidade física, psicológica e da qualidade de vida das populações estão associados à implementação de normas que assegurem a adoção de um modelo de desenvolvimento em bases sustentáveis (BRASIL, 2019).

Em seu artigo $7^{\circ}$, a Resolução $\mathrm{n}^{\circ} 4 / 2019$ alude que "as barragens de mineração inseridas na PNSB devem contar com sistemas automatizados de acionamento de sirenes na ZAS, em local seguro e dotado de modo contra falhas em caso de rompimento da estrutura"

\footnotetext{
${ }^{6}$ Mineração a céu aberto (João Belo ao fundo) B1 em segundo plano e B2 da Yamana Gold em Jacobina. (SILVA, 2018). Foto feita pelo autor do texto Almacks Luis Silva.

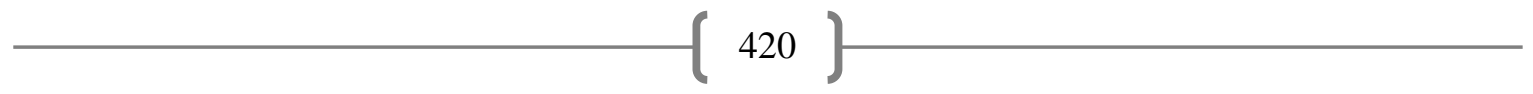

RIET-ISSN 2676-0355, Dourados, v. 2, n. 2, p. 409 a 430, jan./jun., 2021. 


\section{Os Kiriri de Jacobina e os riscos ambientais da exploração aurífera}

(BRASIL, 2019). Vale ressaltar que a Zona de autossalvamento - ZAS vinculadas as B1 e B2 englobam a área do Pontilhão da Canavieira, local exato onde os Kiriri se encontram. Recentemente, em maio de 2020, foi aprovado em Comissão específica, o Projeto de Lei PL. 550/19, que amplia as exigências para as mineradoras no que se refere à segurança das barragens de rejeito. Além de reiterar a proibição do uso de barragens construídas pelo método de alteamento à montante, como a que se rompeu em Brumadinho (MG) em janeiro de 2019, o referido projeto estabelece multa de até R $\$ 1$ bilhão no caso de acidente com essas estruturas. Os riscos de deslizamento das Barragens de rejeitos B1 e B2 (a engenharia admite que não existe obra $100 \%$ segura) são reais e essa previsão de multa não cobre perdas humanas. Com base no citado projeto de lei, é obrigatória, no caso das barragens de rejeito de mineração, a elaboração do Plano de Ação Emergencial - PAE, que discipline todas as ações a serem adotadas na eventualidade de acidentes. O plano é exigido também para as barragens com Dano Potencial Associado - DPA de nível médio. Para determinação do DPA, leva-se em conta o impacto que um possível rompimento ou vazamento pode ocasionar, mesmo que a barragem não seja classificada como de alto risco. O PAE terá que ser apresentado à população local antes que ocorra o primeiro enchimento do reservatório da barragem e implementado em articulação com órgãos de proteção e defesa civil municipais e estaduais.

O supracitado plano, que não está em vigência, deve alcançar as áreas consideradas de maior risco em relação à localização de uma barragem, como: a Zona de Auto-Salvamento (ZAS) à jusante da barragem ( para a qual não há tempo suficiente para socorro); e a Zona de Segurança Secundária (ZSS), fora da ZAS. Essas zonas devem constar do mapa de inundação, que precisa detalhar as áreas potencialmente afetadas por uma inundação e os cenários possíveis para facilitar a notificação eficiente e a evacuação da região.

$\mathrm{Na}$ análise da produção de ouro é importante informar valores de lucratividade da mineradora e o impacto no desenvolvimento econômico do município. Consta, no site do Instituto Brasileiro de Mineração - IBRAM, informes ${ }^{7}$ sobre os investimentos da Yamana

\footnotetext{
${ }^{7}$ além de "reduzir os custos operacionais com um impacto positivo no fluxo de caixa" da operação Município de Jacobina - BA. Por meio de comunicado, a Yamana salientou que o estudo de pré-viabilidade (FPS, na sigla em inglês) da fase 2 está concluído, "com resultados preliminares apontando custos totais de capital de US\$ 57 milhões". "A companhia está avançando em estudos para aprimorar e otimizar ainda mais a Fase 2 como parte do estudo de viabilidade com resultados esperados para meados de 2021", afirma o documento. De acordo com o FPS, do investimento total, US\$ 35 milhões devem ser aplicados na expansão da planta de processamento. Já a mineração subterrânea demandará aporte de US\$ 14 milhões e o os US\$ 8 milhões restantes serão destinados em obras de infraestrutura. (IBRAM, 2020).
}

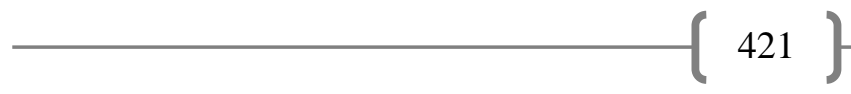

RIET-ISSN 2676-0355, Dourados, v. 2, n. 2, p. 409 a 430, jan./jun., 2021 


\section{Os Kiriri de Jacobina e os riscos ambientais da exploração aurífera}

Gold em Jacobina, bem como sobre projeto de expansão nos seguintes termos: "possibilidade de adiantar a Fase 2 de expansão da mina de ouro Jacobina, na Bahia. O projeto deve consumir investimentos de US\$ 57 milhões. [...]Com a Fase 2, estima elevar a produção de Jacobina para 230.000 onças de ouro por ano" (IBRAM, 2020). Como no passado, a pujança do ouro se contradiz e põe em xeque as afirmações oficiais quanto ao faturamento e lucro da Yamana Gold. No site da ANM, setor de arrecadação, a empresa consta entre os maiores arrecadadores, declarando um faturamento para Compensação Financeira pela Exploração Mineral-CFEM( primeiro quadrimestre de 2020), de R\$ 528.032.142.30. No período da escrita deste trabalho, em comparação do valor da onça de ouro com diversas moedas do mundo, apontava para US\$ 1.708,80, ou seja, aproximadamente $\mathrm{R} \$ 8.616,41$ reais, o faturamento da referida empresa, portanto em uma simples conta de multiplicar, aufere-se para o primeiro trimestre de 2020, o somatório é de 43.938 onças de ouro sobre o faturamento da mineradora, em torno de $\mathrm{R} \$ 378.587 .822,58$ conforme consta no site especializado ${ }^{8}$ e ilustrado em imagem a seguir.

Figura 03 - Arrecadação Yamana Gold 2020

\footnotetext{
${ }^{8}$ https://goldprice.org/pt/gold-price.html que fornece on-line.
} 


\section{Os Kiriri de Jacobina e os riscos ambientais da exploração aurífera}

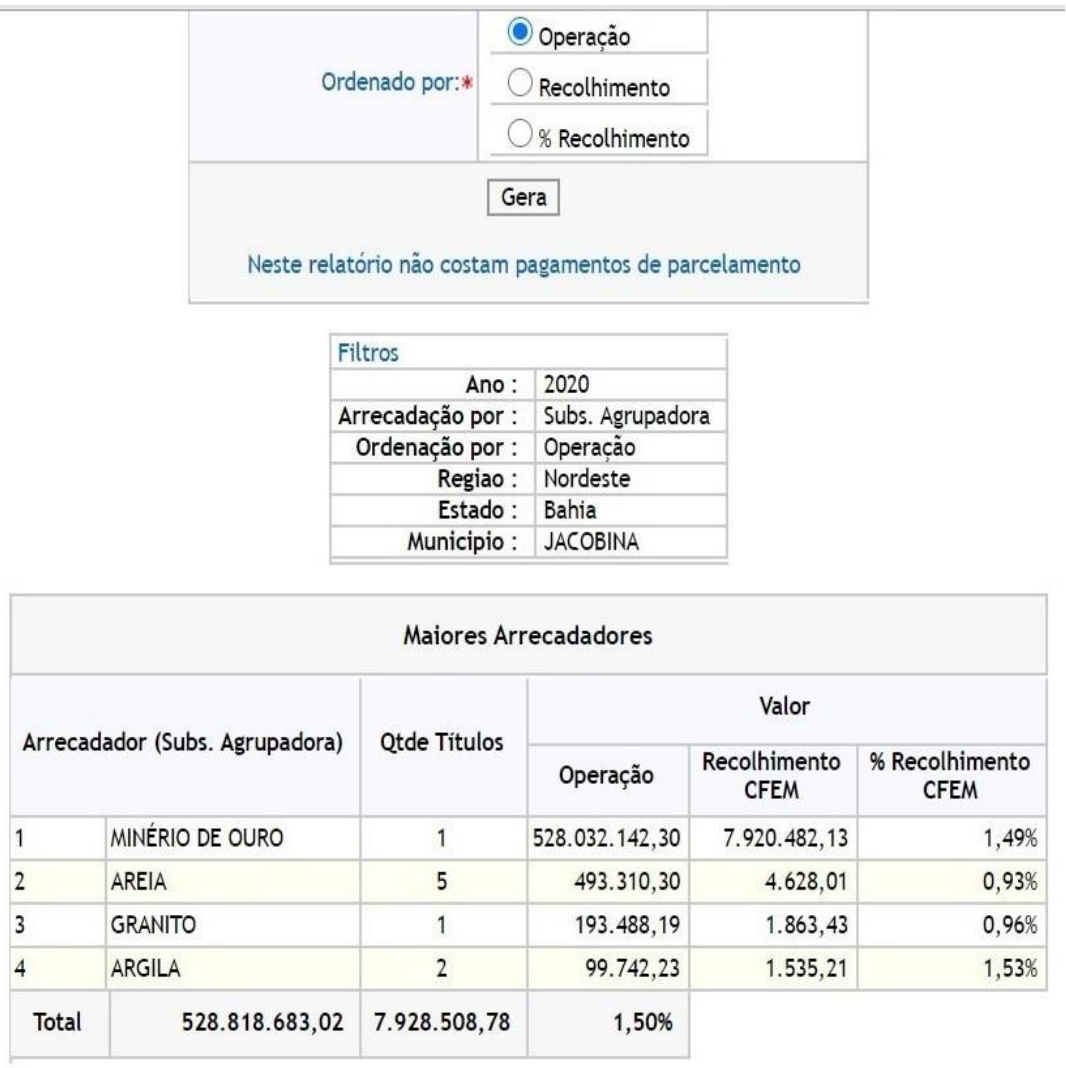

Fonte: Site da Agencia Nacional de Mineração/ 2020

O aumento da extração de ouro, inevitavelmente, impacta na produção de rejeito e consequentemente nas barragens existentes. Sobre possíveis medidas de amortização de desgaste na B1 e B2 paira o silencio da mineradora. O mesmo ciclo de extração lucrativa e miséria ao derredor se mantém, seja no passado com os fazendeiros em Ribeira do Pombal produzindo em terras indígenas, seja atualmente com o capital internacional extraindo minério em Jacobina e ameaçando com barragens desgastadas as terras Kiriri.

\section{A área dos Kiriri em Jacobina}

O Rio Itapicuruzinho, um dos contribuintes do Rio Itapicuru, tem sua nascente literalmente dentro da área da planta da Yamana Gold e ambos pertencem a Bacia Hidrográfica do Rio Itapicuru. De acordo com os estudos de Pinheiro (2004), os rios Canavieiras e Itapicuruzinho, são tributários do Itapicuru-Mirim que é um rio intermitente, cujas nascentes situam-se nos contrafortes da Serra Jacobina, no município de Miguel Calmon, onde hoje se localiza o Parque Estadual das Sete Passagem. Vale ressaltar que "o rio Itapicuruzinho possui um curso de aproximadamente $5 \mathrm{~km}$, têm suas nascentes na área de influência de uma grande mineradora de ouro, atravessa o povoado do Itapicuru e abastece a barragem que distribui água para cidade de Jacobina" (OLIVEIRA, 2013).

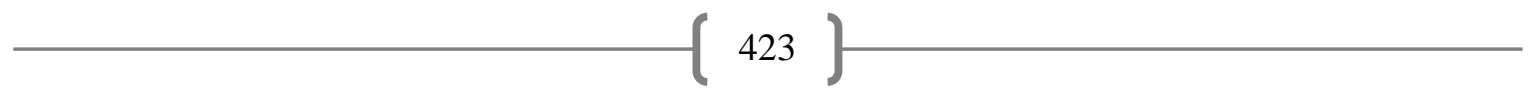

RIET-ISSN 2676-0355, Dourados, v. 2, n. 2, p. 409 a 430, jan./jun., 2021. 


\section{Os Kiriri de Jacobina e os riscos ambientais da exploração aurífera}

Figura 4 - Croqui do potencial hidrográfico da área de atuação da Yamana Gold

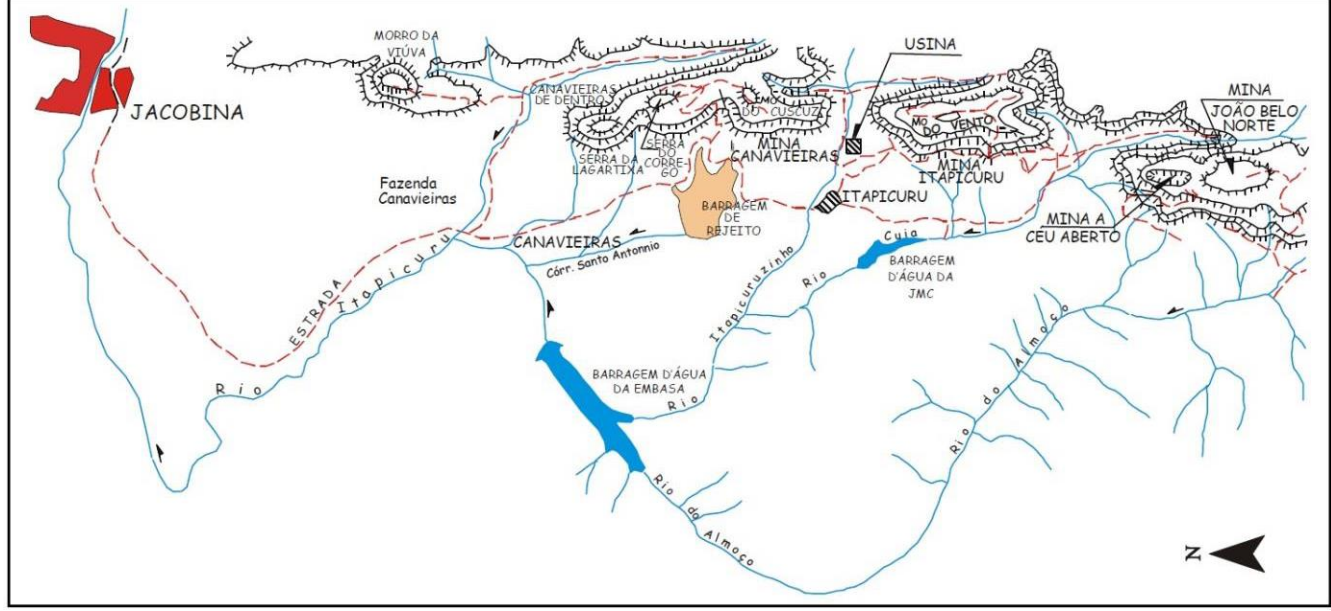

Fonte: Pinheiro ,2004, p. 23

Como se vê no croqui acima, Canavieira está bem abaixo da barragem de rejeito e nesta localidade encontram-se os Kiriri, logo não restam dúvidas, sobre o risco de prejuízo e letalidade, em caso de rompimento de barragem. A partir do relato dos próprios Kiriri, sabe-se que chegaram a Jacobina há 15 anos atrás e foram acolhidos por um fazendeiro que permitiu que eles ocupassem a área em que estão hoje. Esse relato é subsidiado por informações do IBGE sobre a presença indígena nos municípios e baseia-se em alguns parâmetros como: a) Dados mesclados ${ }^{9}$ : são reunidos indígenas e quilombolas numa mesma categoria; b) Autodeclaração ${ }^{10}$ : inclui-se no quantitativo apresentado os indivíduos que se declaram indígenas e aqueles que estão cadastrados pela FUNAI como povo originário; c) Cadastro aleatório ${ }^{11}$ : para além do cadastro da FUNAI e da autodeclaração: existe ainda dados de área ocupadas por indígenas, mas sem sistematização oficial. O quantitativo de 334 indígenas é atribuído ao município de Jacobina e dentre eles, 50 indivíduos, aproximadamente, se identificam dentro dos parâmetros "b" e "c". Em termos percentuais, os Kiriri representam $14,97 \%$ do universo geral de indígenas em terras jacobinenses. No aspecto econômico, os Kiriri cultivam a terra e tem renda basicamente vinculada a produção

\footnotetext{
${ }^{9}$ A Base de Informações sobre os Indígenas e Quilombolas consiste em um conjunto de informações cadastrais, organizadas por municípios, sobre as localidades indígenas e quilombolas estimadas pelo IBGE para a realização dos censos e pesquisas. (IBGE,2020).

10 A base representa todos os lugares do território nacional onde exista um aglomerado permanente de habitantes declarados indígenas ou quilombolas, observando-se o princípio da autoidentificação (Decreto $\mathrm{n}$. 5.051/2004, Convenção 169 da Organização Internacional do Trabalho) (IBGE,2020).

11 São cadastradas as terras indígenas e territórios quilombolas oficialmente delimitados pelos órgãos responsáveis e os agrupamentos de domicílios ocupados por indígenas e quilombolas. São inseridos ainda dados de outras localidades que não atendam aos critérios anteriores, mas que sejam ocupados por indígenas ou quilombolas. (IBGE,2020).
} 


\section{Os Kiriri de Jacobina e os riscos ambientais da exploração aurífera}

e venda de cerâmica, na feira livre da cidade, bem como na estrada de acesso às suas casas, cotidianamente, como se ilustra nas imagens abaixo.

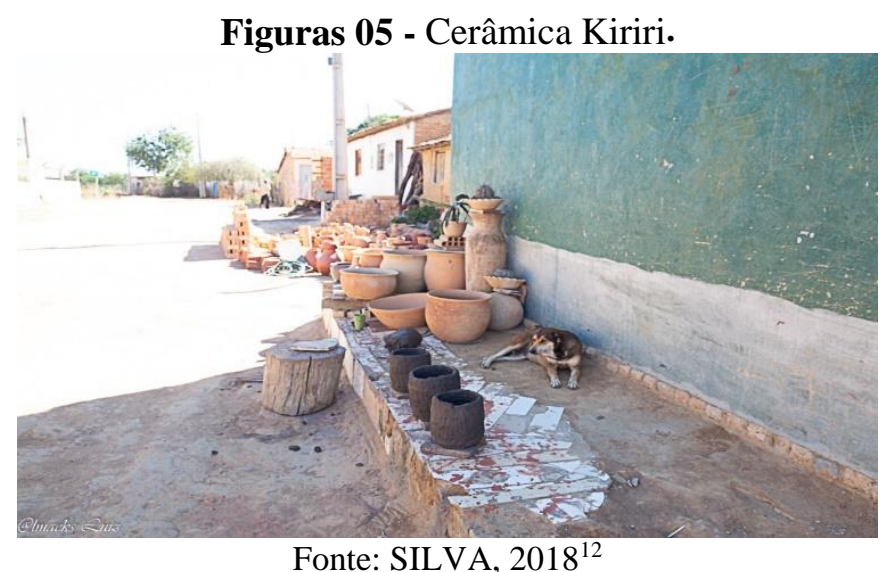

\section{Da Vulnerabilidade Kiriri em Jacobina}

O conceito de vulnerabilidade adotado neste trabalho parte do aspecto social. Brevemente, vulnerabilidade social caracteriza-se pela condição dos grupos de indivíduos que estão à margem da sociedade, em processo de exclusão social, principalmente por fatores socioeconômicos. Neste contexto, pode-se afirmar que a vulnerabilidade dos Kiriri é histórica e com consequências nefastas. Em matérias jornalísticas da década de 70 do século $\mathrm{XX}$, encontram-se referencias bastante significativas que apontam para essa vulnerabilidade social, como por exemplo a descrição da moradia: "As ocas são cabanas de adobe cobertas por palha de Ouricuri[...] de modo geral são pobres e sem condição de higiene" (JORNAL DO BRASIL, 1971). Quanto a alimentação, a mesma matéria jornalística noticia que basicamente comem "feijão, a farinha e carne do sol. Do milho fazem pipocas, paçoca e farinha moída. A caça também é um meio de vida. Os adultos, de um modo geral, são fortes e rijos, mas a maioria das crianças mostram-se desnutridas" (JORNAL DO BRASIL, 1971). As condições de moradia. na referida década, denotavam a vulnerabilidade deste povo pois "quando chove na região, todos passam enormes dificuldades" (JORNAL DO BRASIL, 1971).

A própria luta para demarcação e posse das terras originariamente deste povo demonstra o estado de vulnerabilidade no qual permaneceram por vários séculos, cabendo aqui ressaltar um aspecto, qual seja, a perda de sua representatividade na sociedade, gerando dependência de auxílios de terceiros para garantirem a sua sobrevivência. Tal perda se reflete

\footnotetext{
${ }^{12}$ Fotografia produzida por um dos autores deste trabalho.

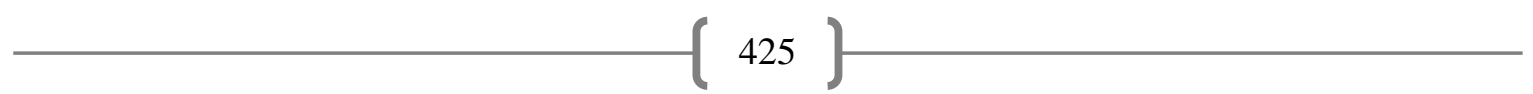

RIET-ISSN 2676-0355, Dourados, v. 2, n. 2, p. 409 a 430, jan./jun., 2021. 


\section{Os Kiriri de Jacobina e os riscos ambientais da exploração aurífera}

nas palavras de CARVALHO (2012, p. 36) que nos "processos contemporâneos de construção sociopolítica e afirmação étnica têm se destacado povos como os Pankararu e os Truká, em Pernambuco, os Potiguara, na Paraíba, os Karirí-Xokó, em Alagoas, e os Kiriri, Tuxá e Tupinambá, na Bahia”. Diante do exposto, percebe-se que a vulnerabilidade dos Kiriri se perpetua na atualidade, pois as condições de posse da terra, habitabilidade, ausência de representatividade e meios de subsistência em Jacobina continuam, e com um agravante: o risco de rompimento de barragem de rejeito. Para além de toda a vulnerabilidade social acima descrita, há a vulnerabilidade ambiental iminente que decorre das condições de desgaste da barragem de rejeito da mineradora em Jacobina e da localização da pequena aldeia Kiriri, exatamente na zona de autossalvamento- ZAS.

\section{Da exposição}

Vale destacar que os indígenas têm proteção normativa diferenciada, pois assim entendeu o legislador constitucional no capítulo VIII da Constituição Federal de 1988. Destaca-se três aspectos importantes com base no Artigo $231 \mathrm{CF} / 88$ que se relacionam com os Kiriri em face da ameaça de rompimento das barragens B1 e B2. O primeiro incide sobre as terras tradicionais, Artigo 231, $\S 1^{\circ}$ :

São terras tradicionalmente ocupadas pelos índios as por eles habitadas em caráter permanente, as utilizadas para suas atividades produtivas, [...] as imprescindíveis à sua reprodução física e cultural, segundo seus usos, costumes e tradições (BRASIL,1988).

Os Kiriri que vivem nas proximidades da Yamana Gold ocupam a terra há mais de 15 anos e dela retiram o sustento e produzem sua arte, a qual também contribui para a subsistência. A arte Kiriri é um traço cultural importante com imbricamento histórico conforme se depreende de SANTOS (2011, p.38), “falantes do kariri, os Payayá podem ser identificados como caçadores-coletores-agricultores, fabricantes de instrumentos de pedra e, possivelmente, conhecedores da produção de cerâmica". Vale salientar que o "uso da cerâmica possivelmente não serviria apenas para a estocagem e cozimento de alimentos, mas também para rituais festivos e fúnebres" (SANTOS,2011, p.38). Na Feira livre de Jacobina, bem como na estrada de acesso à comunidade Kiriri em Canavieira é possível comprar peças de cerâmica a preços baixos.

Outras referências a cerâmica Kiriri aparecem na década de 1970 do século XX quando jornais brasileiros noticiaram que "com exceção dos badoques - feitos com arcos que são utilizados pelos meninos nas caças a passarinhos, até a cerâmica difere da primitiva"

RIET- ISSN 2676-0355, Dourados, v. 2, n. 2, p. 409 a 430, jan./jun., 2021. 


\section{Os Kiriri de Jacobina e os riscos ambientais da exploração aurífera}

(Jornal do Brasil, 1971). Sabe-se que a expressão cultural reafirma a identidade de um povo, portanto deve ser protegida e estimulada. Outro aspecto importante trazido pelo Projeto de Lei, anteriormente analisado, diz respeito ao reassentamento da população, bem como o resgate do patrimônio cultural ou obras de reforço para garantir a efetiva estabilidade da estrutura. Todas essas disposições legais previstas no projeto de lei são necessárias para a proteção mínima da pessoa humana e com destaque para a comunidade Kiriri. A pergunta que não se cala é se elas serão efetivadas.

O segundo aspecto trata-se do usufruto dos corpos d'água pelos Kiriri baseado no parágrafo $2^{\circ}$, Artigo 231CF/88: “terras tradicionalmente ocupadas pelos índios destinam-se a sua posse permanente, cabendo-lhes o usufruto exclusivo das riquezas do solo, dos rios e dos lagos nelas existentes" (BRASIL,1988). Depreende-se que qualquer situação de contaminação ou destruição de corpo d'água que prejudique o povo Kiriri, (como a que se denuncia neste texto) é descumprimento de preceito constitucional.

Terceiro e último aspecto incide sobre a Proteção dos Kiriri e das águas ante o descumprimento do parágrafo $3^{\circ}$ do supracitado artigo:

O aproveitamento dos recursos hídricos, incluídos os potenciais energéticos, a pesquisa e a lavra das riquezas minerais em terras indígenas, só podem ser efetivados, com autorização do Congresso Nacional, ouvidas as comunidades afetadas (BRASIL, 1988).

Pelo já relatado neste artigo, a comunidade Kiriri já tem dificuldade para aproveitar o recurso hídrico do Rio Itapicuruzinho, devido a poluição notificada através do inquérito civil já citado neste trabalho, e se houver ruptura de barragem, tais dificuldades se intensificarão.

\section{Considerações Finais}

Em caso de rompimento das barragens B1 e B2 as consequências são seríssimas, pois atinge uma grande extensão territorial da cidade de Jacobina, além de atingir a área ocupada pelo povo Kiriri. Esse alcance gera vítimas fatais e perda de moradia. Na verdade, gera uma desagregação social, dentre as muitas, pelas quais os Kiriri já passaram no passado. Em um segundo plano inviabiliza o modus de vida da comunidade Kiriri, pois sem terra ou com terra contaminada por produtos químicos usados na mineração, não há produção.

No plano hídrico, em caso de deslizamento, há comprometimento dos corpos d'água e consequente no abastecimento de água potável. Há ainda possíveis dificuldades

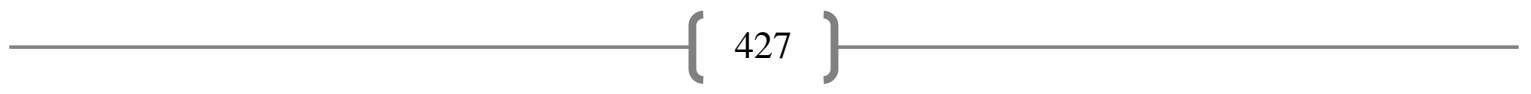

RIET- ISSN 2676-0355, Dourados, v. 2, n. 2, p. 409 a 430, jan./jun., 2021. 


\section{Os Kiriri de Jacobina e os riscos ambientais da exploração aurífera}

para recebimento de valores indenizatórios ou reassentamento populacional, pois não há a posse regular da terra por parte dos Kiriri, nem o reconhecimento de seu pertencimento étnico. A intensificação da vulnerabilidade social e ambiental dos Kiriri é inequívoca em caso de ruptura das barragens mencionadas.

Diante de todo o exposto verifica-se que existem percursos históricos e linguísticos dos Kiriri em terras jacobinenses que se perpassam e se cruzam muito tempo. Reitera-se que a atividade mineradora em Jacobina coloca em risco o modo de vida do agrupamento Kiriri na localidade de Pontilhão da Canavieira.

O risco principal ao que esse povo indígena está exposto é de caráter ambiental devido os desgastes da barragem de rejeito e uma possível ruptura, mas apesar deste risco, nenhuma atitude preventiva, efetivamente, em relação a zona de autossalvamento foi empreendida. Verifica-se que há claro descumprimento da legislação protetiva ao indígena brasileiro, portanto aplicável aos Kiriri, por serem estes econômica, social e culturalmente vulneráveis.

O entendimento constitucional de meio ambiente é extensivo às gerações presentes e futuras, ou seja, deve-se mitigar risco e reduzir a vulnerabilidade Kiriri como expressão de proteção ao meio ambiente.

\section{Referencias}

BAHIA. Inquérito Civil no 702.9.76928/2017. Ministério Público do Estado da Bahia. Seção Jacobina. 2017.

BRASIL, Relatório Nacional de Segurança de barragens 2020. Disponível em: http://www.inema.ba.gov.br/gestao-2/barragensreservatorios/relatorio-segura-barragens/. Acesso em $15 / 05 / 2020$.

BRASIL, Resolução No 4, De 15 De Fevereiro De 2019. Estabelece medidas regulatórias cautelares objetivando assegurar a estabilidade de barragens de mineração, notadamente aquelas construídas ou alteadas pelo método denominado "a montante" ou por método declarado como desconhecido. Diário Oficial da União. 18/02/2019. Edição 34. Seção 1. Página: 58.

BRASIL. Constituicão da República Federativa do Brasil de 1988. Diário Oficial da União de 05/12/1988. P.1

BRASILEIRO. Sheila. Kiriri. Disponível em: https://pib.socioambiental.org/pt/Povo:Kiriri. 2018. Capturado em 01/06/2020.

CARVALHO, Maria Rosário; CARVALHO, Ana Magda. Índios e caboclos: a história recontada [online]. Salvador: EDUFBA, 2012. ISBN 978-85-232-1208-7. Disponível em:

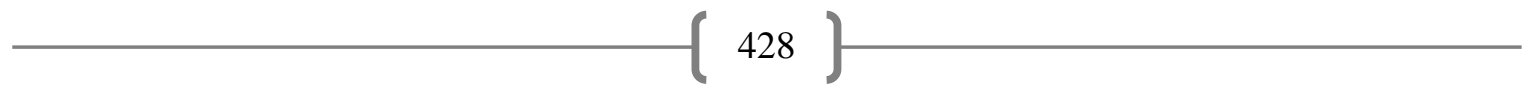

RIET-ISSN 2676-0355, Dourados, v. 2, n. 2, p. 409 a 430, jan./jun., 2021. 


\section{Os Kiriri de Jacobina e os riscos ambientais da exploração aurífera}

https://static.scielo.org/scielobooks/mv4m8/pdf/carvalho-9788523212087.pdf. Acesso em $15 / 05 / 2020$.

CONCEIÇÃO. Hélida Santos. Governando a periferia: A criação da comarca da parte do Sul da Bahia no Império Ultramarino Português - Século XVIII.. 2017. Disponível em XII Jornada de Estudos Históricos. Rio de Janeiro. Anais da XIII Jornada de Estudos Hstóricos professor Manuel salgado. PPGHIS/UFRJ. Vol. 3.

FARIAS, Sara Oliveira. Enredos e Tramas nas Minas de ouro de Jacobina/ Sara Oliveira Farias - Recife- 2008. 237 fl.: il Orientador Antonio Torres Montenegro. Tese (doutorado) Universidade Federal do Pernambuco.2008.

HTTPS://goldprice.org/pt/gold-price.html que fornece on-line. Acesso em 19/8/2020 IBRAM. Portal da Mineração / Notícias / Notícias Gerais 2020. Yamana pretende acelerar 2a fase de expansão da mina de ouro Jacobina(BA). Noticias de Mineração Brasil. 04/05/2020. Disponível em: http://portaldamineracao.com.br/ibram/yamana-pretende-acelerar-2a-fase-deexpansao-da-mina-de-ouro-jacobinaba/.

JESUS, Zeneide Rios. Eldorado sertanejo: garimpos e garimpeiros nas serras de Jacobina (1930 - 1940). Salvador. Dissertação de mestrado, UFBA. 2005

JORNAL DO BRASIL. Indios Kiriri perdem antigos costumes e se entregam ao alcoolismo. 12e $13 / 12 / 1971.1^{\circ}$ caderno. P. 38. Disponível em: https://www.socioambiental.org/pt-br/oisa/programas/povos-indigenas-no-brasil. Acesso em 25/05/2020.

KIRIRI, Dernival. Povos indígenas no Brasil. Disponível em: https://pib.socioambiental.org/pt/P\%C3\%A1gina_principal. 2014. Acesso em 25/05/2020. LIMA, Sabrina de Souza; SANTOS, Laudiceia da Cruz; SILVA, Jeronimo Jorge Cavalcanti. Reconhecimento De Coletivos Diversos No Ceep Felicidade De Jesus Magalhães: Uma Experiência Pedagógica Com Povos Tradicionais - Negros, Ciganos E Indígenas. In: V CONEDU, 2018.

OLIVEIRA, Céurio de. Dicionário Cartográfico. 2a ed. Rio de Janeiro: IBGE, 1983. PAGLIARO, H., AZEVEDO, MM., and SANTOS, RV., orgs. Demografia dos Povos Indígenas no Brasil [online]. Rio de Janeiro: Editora FIOCRUZ; Campinas: Associação Brasileira de Estudos Populacionais - ABEP, 2005. ISBN 978-85-7541-254-1. Edição Kindle

PINHEIRO, Christiane Freitas. Avaliação geoambiental do município de Jacobina-Ba através das técnicas de geoprocessamento: um suporte ao ordenamento territorial. Salvador, 2004. 267 f. Dissertação (Mestrado) - PósGraduação em Geografia. Universidade Federal da Bahia. Instituto de Geociências.

REESINK, E. A maior alegria do mundo: a participação dos índios Kiriri em Belo Monte (Canudos). In: CARVALHO, MR., and CARVALHO, AM., org. Índios e caboclos: a história recontada [online]. Salvador: EDUFBA, 2012, pp. 243-256. ISBN 978-85-232-1208-7. Available from SciELO Books .

RODRIGUES, Adam. Karirí como família linguística Macro-Jê no Nordeste do Brasil. In: Revista Brasileira de Linguística Antropológica, 2019. Volume 11. N1. Disponível em: https://periodicos.unb.br/index.php/ling/article/view/26441. Acesso em 25/05/2020.

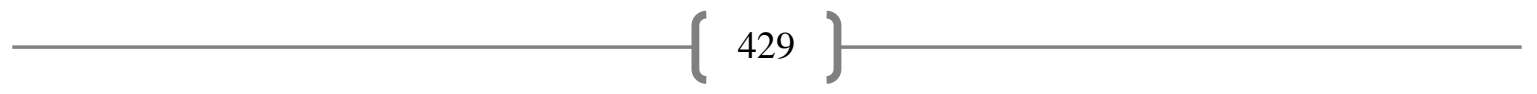

RIET-ISSN 2676-0355, Dourados, v. 2, n. 2, p. 409 a 430, jan./jun., 2021. 


\section{Os Kiriri de Jacobina e os riscos ambientais da exploração aurífera}

SANCHES, NANCI. A exploração aurífera na Bahia oitocentista: decadência, desgaste ambiental e desordem social. In: estudoscolaborativos.sei.ba.gov.br. 2017.Bahia. Acesso em 25/05/2020.

SANTOS, Solon Natalício Araújo dos. Conquista e Resistência dos Payayá no Sertão das Jacobinas: Tapuias, tupi, colonos e missionários (1651-1706). Dissertação apresentada ao Programa de Pós-Graduação em História da Faculdade de Filosofia e Ciências Humanas da Universidade Federal da Bahia. 2011. Orientadora: Prof ${ }^{\mathrm{a}}$. Dr ${ }^{\mathrm{a}}$. Maria Hilda Baqueiro Paraíso. SILVA. Almacks Luis. Fotografia cerâmica Kiriri. Disponível em: https://www.instagram.com/almacksluizsilva/.2018.

VIEIRA FILHO. Rafael. Educação nas Jacobinas - período colonial e imperial. Natal. 2002. Disponível em http://sbhe.org.br/novo/congressos/cbhe2/pdfs/Tema7/0735.pdf. Acesso em $\underline{01 / 06 / 2020 .}$.

WWW.ibge.gov.br/. Acesso em 03/06/2020

WWW.ana.gov.br/noticias/ana-lanca-relatorio-de-seguranca-de-barragens-2018. Acesso em $23 / 9 / 2020$

WWW.gov.br/anm/pt-br. Arrecadação. Acesso em 12/7/2020.

RIET- ISSN 2676-0355, Dourados, v. 2, n. 2, p. 409 a 430, jan./jun., 2021. 